\title{
Sublethal Effects of Pyrethroids on Insect Parasitoids: What We Need to Further Know
}

\author{
Patrícia Garcia \\ Universidade dos Açores \\ Departamento de Biologia, R. Mãe de Deus, Apt 1422, 9501-855 Ponta Delgada \\ Centro de Investigação e Tecnologias Agrárias dos Açores (CITA-A), \\ Azorean Biodiversity Group, Angra do Heroísmo \\ Portugal
}

\section{Introduction}

In the past decade pyrethroids have emerged as a major class of highly active insecticides due to their high bio-efficacy and relatively low toxicity in comparison to organochlorine and organophosphate pesticides, which are more acutely toxic to birds and mammals than the pyrethroids. These chemicals have been largely used for the control agricultural pests, with Lepidoptera representing the highest percentage (40\%) of pyrethroid targeted insects, followed by sucking insects and Coleoptera (Wirtz et al., 2009). On the other hand, insect parasitoids are of high importance in natural and agricultural ecosystems where they regulate or influence the population density of their hosts, being therefore worldwide used in the control of several agricultural pests, particularly Lepidoptera and Hemiptera.

Parasitoids can be released in the field either by inundative (for an immediate and non sustaining reduction of the target host population) or inoculative (where the objective is to release the natural enemies early in the season and so is the progeny who will have a later effect on the target host population) approaches. In the first approach, parasitoids are positioned as a fast-acting replacement of insecticides, while in the second parasitoids are considered as one aspect of integrated pest management (Smith, 1996). According to the review by Collier and Steenwyk (2004), biological control by augmentative releases of natural enemies is not likely to replace insecticides in the near future, in part due to the apparent lack of efficacy compared to conventional insecticide applications. Thus the integration of biological and chemical controls is an essential alternative to the conventional use of insecticides that requires knowledge of the lethal and sublethal effects that chemicals may have on the natural enemies. Actually most of the studies regarding the effects of insecticides (inclusive for pyrethroids) on parasitoids and other natural enemies have relied on the evaluation of acute toxicity by determination of a median lethal dose $\left(\mathrm{LD}_{50}\right)$ or concentration $\left(\mathrm{LC}_{50}\right)$ (Desneux et al., 2007). Though estimation of $\mathrm{LD}_{50}$ or $\mathrm{LC}_{50}$ is a simple and a fast approach to compare and evaluate the acute toxicity of insecticides to parasitoids, it overlooks sublethal effects that will interfere with the physiology and behaviour of the natural enemies. Insecticides may directly interfere with the efficacy of biological control 
agents by changing biological traits, such as, fecundity, fertility, longevity, developmental rates, emergence rates, or indirectly, by modifying behavioural traits that will affect the interactions between parasitoids and their hosts.

In view of the current literature, this chapter aims to cover the main sublethal effects of pyrethroids on insect parasitoids and then discuss the need to develop further research on physiological and behavioural effects that are considered important to the success of insect pest management programs. The chapter is organized as follows. The first section deals with a brief explanation of what are pyrethroids, discussing their role in agriculture nowadays. The second section is dedicated to the knowledge of the main aspects of the biology of insect parasitoids (particularly of egg and larval parasitoids) and makes a summarizing overview of their current use in biological control and Integrated Pest Management (IPM) programs. The third section reviews the lethal and sublethal effects of pyrethroids on parasitoids published in the past 10 years, highlighting the studies that cover the effects of these insecticides on physiological and behavioural traits.

\section{Pyrethroids}

\subsection{What are pyrethroids?}

Pyrethroids are neurotoxic manufactured insecticides that are very similar in structure to the pyrethrins, but are often more toxic to insects as well as to mammals, and last longer in the environment than the pyrethrins. Pyrethrins are naturally-occurring insecticidal esters of chrysanthemic acid (pyrethrins I) and pyrethric acid (pyrethrins II), originally found in the flowers of Chrysanthemum cinerariaefolium (Asteraceae) and C. coccineum (Todd et al., 2003; Davies et al., 2007). Pyrethrin-I, cinerin-I, and jasmolin-I are esters of chrysanthemic acid whereas pyrethrin-II, cinerin-II, and jasmolin-II are esters of pyrethric acid (Essig \& Zhao, 2001).

The use of crushed and powdered Chrysanthemum plants as an insecticide by the Chinese dates back $1^{\text {st }}$ century AD and by the Middle Ages were to be found in Persia. The "Persian Insect powder", produced from dried flowers of Chrysanthemum roseum and C. cinerariaefolium, became known and sold in Europe via Armenian traders in the beginning of 19th century (Housset \& Dickmann, 2009). In the mid of 19th century, the commercial production of pyrethrins from Chrysanthemum flowers started at full-scale, and the chief active chemicals in the extract (pyrethrins I and II) are still in use nowadays in many household sprays and products to control insects on pets or livestock (Davies et al., 2007). Insects can become resistant to pyrethrins via the production of enzymatic detoxifiers, thus these active chemicals are usually commercialized in combination with the synergists piperonyl butoxide and n-octyl bicycloheptene dicarboximide that retard enzymatic degradation of pyrethrins within the insect (Reigart \& Roberts, 1999). Moreover, pyrethrins degrade rapidly when exposed to natural sunlight (thus not persisting in the environment beyond a few weeks), so their use for the control of agricultural pests is limited; this issue was surmounted in the 1970s by the structural modification of pyrethrins (Todd et al., 2003), resulting in the production of synthetic pyrethroids that presently account for $15 \%$ of the world insecticide market (Wirtz et al., 2009). Currently pyrethroids are formulated as emulsifiable concentrates, wettable powders, granules, and concentrates for ultra low volume application, being worldwide used in agriculture, in homes and gardens, and for treatment of ectoparasitic diseases, through the commercialization of more than 50 distinct commercial products (Reigart \& Roberts, 1999). 
There are two types of synthetic pyrethroids that differ in chemical structure: Type I pyrethroids (allethrin, bifenthrin, permethrin, phenothrin(Bio), resmethrin, tefluthrin and tetramethrin) are derivatives of pyrethrins that do not include a cyano group and may elicit tremors, and type II pyrethroids (cyfluthrin, cyhalothrin, cypermethrin, deltamethrin, fenvalerate, fenpropathrin, flucythrinate, flumethrin, fluvalinate and tralomethrin) are derivatives of pyrethrins that include a cyano group and may elicit sinuous writhing and salivation (Todd et al., 2003). Synthetic pyrethroids and pyrethrins affect both the peripheral and central nervous system of insects, by acting on the voltage-gated sodium channel proteins found in nerve cell membranes. By prolonging the opening of these channels, pyrethrins and pyrethroids stimulate nerve cells to produce repetitive discharges, causing paralysis (known as insect 'knockdown') and possible insect death (Gunasekara, 2004; Davies et al., 2007). While the development of synthetic pyrethroids was done towards a selective toxicity to insects, they are also highly toxic to many aquatic organisms, inclusive fish (Todd et al., 2003). Though the systemic toxicity by inhalation and dermal absorption of pyrethroids is low for mammals, certain pyrethroids show a high neurotoxicity when administered by intravenous injection, and some are toxic when ingested. In addition to the limited dermal absorption, the low systemic toxicity is also related to the rapid biodegradation of pyrethroids by mammalian liver enzymes (Reigart \& Roberts, 1999).

\subsection{Current status of pyrethroids in agriculture}

After more than 30 years on the market, the role of pyrethroids in modern pest control is still significant today. Synthetic pyrethroids represent the $3^{\text {rd }}$ largest class of chemical insecticides after organophosphates and chloronicotinyl insecticides (CNI, or neonicotinoids), with a market value of 1,300 Mio. US\$, a share of $15 \%$ of the global foliar and soil insecticide markets and 320 Mio. hectares of treated agricultural area (Wirtz et al., 2009). Pyrethroids are worldwide used in over 300 distinct crops, being their use particularly relevant for the control of agricultural pests of the following crops: fruit (apples, peaches, etc.), grain (sweet and field corn) and vegetables (soybeans, peppers, Brussel sprouts, cucumbers, broccoli, peas, cabbage, tomatoes, potatoes, etc.). Vegetable and flower crops represent $>40 \%$ of pyrethroid targeted crops in the market, followed by corn and other cereals $(30 \%)$ and, fruit and nuts (15\%); regarding the targeted pests, these chemicals have been largely used for the of Lepidoptera ( $40 \%$ of pyrethroid targeted insects), followed by sucking insects (32\%) and Coleoptera (20\%). Though currently farmers have commercially available pyrethroids-based ready-mixtures, they still prefer to use straight pyrethroids products, due to their compatibility with other compounds which allows farmers to mix pyrethroids whenever practical. Even so the market share of pyrethroids-based readymixtures has grown strongly and constantly over the last years, particularly for pyrethroidCNI mixtures (Wirtz et al., 2009). Mixing pyrethroid with neonicotinoids results in a product where the effects from active substances from both chemical classes complement each other, either regarding their mode of action (acting on the sodium channel or on the nicotinic acetylcholine receptor), via of contact (absorption/ingestion or systemic) and, their immediate or residual effects. Furthermore, given that pyrethroids are insecticides of broad spectrum and of low cost, the use of pyrethroid-CNI mixtures reduces the cost of only using neonicotinoids. The market share of pyrethroid-CNI mixtures is expected to be particularly relevant in the major emerging countries such as China, India and Brazil, where the impact of climate change and the growing population will promote the need for higher yield and 
quality products, while fulfilling the environmental safety requirements (Smith et al., 2008; Wirtz et al., 2009). To contribute to IPM programmes, these chemicals are required to be highly specific and selective (products must be benign to non-target species ranging from aquatic species through to beneficial insects), show benign environmental and toxicological profiles, and be biodegradable (Smith et al., 2008).

\section{Insect parasitoids}

\subsection{Parasitoid definitions and natural history}

Parasitoids are insects whose larvae develop by feeding on the bodies of other arthropods, usually insects, eventually resulting on the death of their host, and a single host provides all the food required for the development of the parasitoid into an adult. They represent about $8,5 \%$ of all the described insect species, although this value may rise up to $20 \%$ given that many workers argue that parasitoids are relatively poorly known (Godfray, 1994). Parasitoids are holometabolous insects (their life cycle is divided in 4 stages - egg, larva, pupa and adult), that can develop to adult singly from one host or gregariously on the same host (gregarious parasitoids). Gregarious parasitism may be the result of multiple eggs laid on or in a single host, or it may result from the repeated division of a single egg, being in this case termed as polyembryony (Gauld \& Bolton, 1988).

After oviposition, the host is either killed or permanently paralyzed (idiobiont parasitoids), so the parasitoid larvae is limited to the host resources present at the moment of oviposition, or it is maintained alive or only temporarily paralyzed, and after recover continues to feed until it dies due to parasitoid development and feeding (koinobiont parasitoids). Parasitoids can be further classified as endoparasitoids, which develop inside the host, and ectoparasitoids, which develop outside the host body, though they are frequently attached or embedded in the host tissues. In some cases the female lays the eggs on the host's foodplant and parasitism occurs either when the host eats the parasitoid eggs or when there is a free-living first instar parasitoid larva that actively searches for the host. Adult parasitoids may feed from several energy sources, such as flowers, sap fluxes, and even from potential hosts, a behaviour designated host feeding. Parasitoids are classified as egg, larval, pupal or adult parasitoids when they parasitize respectively the egg, larva, pupa or adult host stage. Some parasitoids may lay the eggs in one host stage but their progeny only emerges until the host has entered a later stage, being therefore designated as egg-larval or larval-pupal parasitoids. Egg, pupal and adult parasitoids, as well as larval parasitoids whose sting causes permanent paralysis of the host, are usually idiobionts while the remaining usually are koinobionts. Idiobionts that attack concealed hosts are usually ectoparasitoids, while those attacking exposed hosts are in general endoparasitoids. Koinobionts are in majority endoparasitoids and usually attack exposed or weakly concealed hosts. Generalist parasitoid species are able to develop in several host species, while specialists can only develop on one or few closely related host species. Species that are parasitoids of other parasitoids are designated hyperparasitoids. Sex determination in hymenopteran parasitoids is haplodiploid, being the males generally haploid (unfertilized eggs develop to become males), while individuals developing from fertilized eggs become females; this type of reproduction is termed arrehenotoky. Some parasitoids reproduce asexually by thelythokous parthenogenesis; in these case diploid females produce a diploid female progeny by a variety of asexual mechanisms. One relevant aspect of arrenothokous parthenogenesis is the ability of females to determine the offspring sex ratio by altering the 
proportion of laid fertilized eggs, in response to distinct factors, such as host size, host distribution and abundance (Gauld \& Bolton, 1988; Godfray, 1994; Quicke, 1997).

Regarding parasitoid diversity, these insects are mainly from the order Hymenoptera (with about 50000 described parasitoids), followed by the order Diptera (with about 15000 described parasitoids), being the remaining species (about 3000) from other orders, such as Coleoptera. For Hymenoptera, parasitoids within the superfamily Ichneumonoidea represent half of the described parasitoids (about 25000 species) followed by the Chalcidoidea ( $>17500$ species). Within the order Diptera, the family Tachinidae with 8200 described parasitoid species represents more than half of dipteran parasitoids (Godfray, 1994).

\subsection{Parasitoids and insect pest management}

Due to their life histories, parasitoids have an important role in natural and agricultural ecosystems by influencing and regulating the population density of their hosts. According to Van Lenteren (1986) more than $80 \%$ of the successful natural enemies are parasitoids, being the remainder predators $(17 \%)$ and pathogens $(1 \%)$. The role of parasitoids in the natural and agricultural ecosystems has enhanced many studies, generating a vast quantity of information on the behaviour and ecology of several distinct genera and species (Godfray, 1994); Van Lenteren (1986) estimated that up to that date, 5000 species have been tested for use in biological control and out of these, 270 species have led to partial (100), substantial (100) or complete control (70). Parasitoids can be released to the field by an inundative approach to achieve an immediate, non-sustaining reduction of the target pest or by an inoculative approach, in which few parasitoids are required early in the season because it is the progeny that will have a later effect on the target pest; therefore, in inoculative release the parasitoid must be faced as one aspect of IPM. The choice of the release approach is based on established criteria for pre-introductory evaluation of natural enemies. Among such criteria, synchronization with the host (both seasonal and internal), host specificity and high reproductive potential are quite relevant when using an inoculative approach, while for inundative the more relevant factors are adaptation to the climatic conditions of the environment and a good mass rearing method (Van Lenteren, 1986). According to Greathead (1986), in classical biological control (the introduction and permanent establishment of an exotic biological control agent) three taxa stand out as major sources of parasitoids: Ichneumonoidea and Chalcidoidea (Hymenoptera), and Tachinidae (Diptera). Within Ichneumonoidea, Braconidae and Ichneumonidae are families that have a broad range of hosts and life cycles. Braconidae are usually egg-larval or larval parasitoids of aphids, bark beetles, and foliage-feeding caterpillars; the genera Apanteles s.l., Bracon s.l. and Opius s.l. are within this family the more important groups of wasps used in biological control. Ichneumonidae wasps attack larvae or pupae of flies, caterpillars, beetles and sawflies; their eggs are usually placed inside the host larvae and develop internally, though a few are ectoparasitoids, feeding on the outside of the host. Within the superfamily Chalcidoidea, most of the species are parasitoids of other insects, attacking the egg or larval stage, though many other life cycles are known; the most relevant wasps in biological control are from the families Eulophidae, Pteromalidae, Encyrtidae and Aphelinidae (Greathead, 1986). Regarding Diptera, the family Tachinidae ranks with the more important families of Hymenoptera as a source of biological control agents; tachinid larvae are internal parasitoids of many insects, especially Lepidoptera and, their oviposition and larviposition strategies are very diverse, varying from those which lay eggs and wait for the host larvae to 
find them, to other species which retain the egg until it is about to hatch before inserting it into the body of the host (Greathead, 1986).

In biological control, using egg parasitoids over larval for the control of pests has the advantage of preventing the hatch of the host prior it causes major damages; furthermore, egg parasitoids are also easier to mass rear given that these wasps usually are less hostspecific than larval parasitoids. The most successful families of egg parasitoids in biological control are Scelionidae, Mymaridae and Trichogrammatidae (Greathead, 1986).

Among Trichogrammatidae, the genus Trichogramma (Hymenoptera: Trichogrammatidae) as been considered for the control of lepidopterous pests for more than 100 years (Smith, 1996). The genus Trichogramma is worldwide distributed and consists of about 145 described species. These minute wasps $(0,2-1,5 \mathrm{~mm})$ have a preference for Lepidoptera, but there also records of parasitism from eggs of Coleoptera, Diptera, Hemiptera, Homoptera, Hymenoptera (Symphyta) and Neuroptera (Pinto \& Stouthamer, 1994). Thelytoky is described for 10 Trichogramma species and is associated with an infection of the wasps with Wolbachia bacteria (Stouthamer et al., 1993). Arrhenotokous lines of these species can be started either by treating thelytokous females with antibiotics (tetracycline, rifampicin or sulfamethoxazole) or by rearing the parasitoids at temperatures above $28^{\circ} \mathrm{C}$ (Pintureau et al., 1993; Stouthamer \& Werren, 1993). A species with both modes of reproduction allows the choice of which form to use in a biological control release: for inundative release thelytoky seems to be in advantage, given that the production costs per female are lowered; for inoculative releases, Stouthamer (1993) suggested that the thelytokous strains should be used when hosts are very patchily distributed because of their superior colonization characteristics. On the other hand, the sexual strains will likely be able to adapt faster to changing circumstances so they should preferentially be used for inoculative releases, where parasitoids are expected to be and reproduce in the fields for a larger period.

Research on the use of Trichogramma in biological control initiated in the second decade of the $20^{\text {th }}$ century and a method to mass produce these wasps using Sitotroga cerealella Olivier (Lepidoptera: Gelechiidae) was developed in 1930 in the USA (Hassan, 1993); yet, the mass rearing and release of these wasps only fully began in Europe and North America in the 1970s (Smith, 1996). Since 1975, several species of Trichogramma have been used to control pests of over 20 different crops (e.g., cotton, sugar-beet, cabbage, corn, rice, sugar-cane, soybean), in more than 50 countries from all over the world being reported to be used commercially on more than 32 million ha each year (Li-Ying, 1994; Smith, 1996). Although there are almost 20 years apart between the reviews made by Stinner (1977) and by Smith (1996), both authors emphasise on integrating Trichogramma with other control options, particularly in combination with selective insecticides.

Aphid parasitoids (Hymenoptera, Braconidae) are also well recognized worldwide for their importance in controlling aphid pests within a range of cropping system, with more than 400 different species documented. The female parasitoid oviposits into the host but the aphid is only killed prior to parasitoid pupation, being only kept the skin of the host, termed as mummy. The parasitoid then completes the development to adult, which emerges from the host (Longley, 1999).

The immature stages (egg, larva and pupa) of both egg and aphid parasitoids can be often protected from insecticide applications since parasitoids are housed within the host egg chorion or host skin during their development, being therefore key stages for IPM programs. 


\section{Sublethal effects}

Integrated pest management combines chemical, biological, and cultural control to provide targeted and efficient pest management solutions that can be tailored to specific climates and habitats in order to maximize a program's efficacy (Gentz et al., 2010). However, and in addition to the development of pest resistance (Denholm et al., 2001), the extensive use of insecticides in crop systems surely has effects on non-target organisms. Among these effects, the reduction of the efficiency of biological control agents, such as parasitoids, has been highlighted by several authors (Cross et al., 1999; Sterk et al., 1999; Brunner et al., 2001; Hewa-Kapuge et al., 2003). Since insecticides may cause the death of the biological control agents (lethal effects) or change several other traits of their biology (either physiological or behavioural) without killing the individuals (sublethal effects), the success of IPM programs depends, in part, on the optimal use of selective insecticides that are less harmful to natural enemies. Thus, in addition to direct mortality induced by insecticides, we should also have knowledge of the effects on physiological and behavioural traits of the natural enemies for a complete analysis of the insecticides impact (Desneux et al., 2007; Stark et al., 2007a).

The main routes of pyrethroid exposure for adult parasitoids or for ectoparasitoids are uptake after direct exposure to spray droplets, uptake of residues by contact with contaminated surfaces, e.g. soil or vegetation, and oral uptake from contaminated food sources (Langley \& Stark, 1996), e.g. when parasitizing and/or feeding on insecticide-treated host. Endoparasitoids are mainly exposed to pyrethroids trough the uptake of residues from insecticide-treated host upon the emergence of the adult, or by contact with the active ingredient after its penetration trough the host skin or chorion, being therefore more often protected than adults or ectoparasitoids. Pyrethroids are considered harmful (mortality $>99 \%$ ) to insect parasitoids, particularly to adults; nevertheless, when testing the less susceptible life stages of endoparasitoids (e.g., larval or pupal stages), there is reduction in the mortality, lowering the evaluation category to slightly harmful (30-70\% of mortality) (Sterk et al., 1999). According to the review made by Longley (1999), organophosphate insecticides prove to be generally more toxic to developing aphid parasitoids within mummified hosts than pyrethroid compounds (pyrethroids were included by the authors in a rank that gives mortalities between 21-30\%, while organophosphates ranked for mortalities between 51-60\%). However, even if immature stages of insect parasitoids might be less susceptible to pyrethroids, these insecticides most probably have effects on the wasp's longevity, fecundity, developmental rates, sex ratios, mobility, etc., and therefore such traits should also to be considered when assessing the side effects of insecticides on beneficial organisms. Even such approaches show the consequences of any detrimental side effects of pyrethroids that otherwise go undetected in the standard direct mortality assessments, they are laborious to perform and so are frequently ignored by researchers.

A revision of the sublethal effects of pyrethroids on parasitoids published in the past 10 years is made in this section, highlighting the studies that cover the effects of these insecticides on physiological and behavioural traits. Information regarding the main sublethal effects analysed in these studies is summarized in Table 1.

\subsection{Physiological traits}

The effects of insecticides caused by direct contact with the toxin are manifested as shortterm mortality or relatively long-term sublethal effects. The majority of the studies that evaluate the side effects of pyrethroids on natural enemies report primarily to short-term 
mortality by directly analyzing the mortality of adults and immature stages and, indirectly trough the evaluation of the emergence of parasitoids from the host (e.g., Tillman \& Mulrooney, 2000; Kok \& Acosta-Martinez, 2001; Raposo et al., 2003; Symington, 2003; Youssef et al, 2004; Prabhaker et al., 2007; Wang et al., 2008). However, in the last years the number of studies that additionally report to the sublethal effects of pyrethroids has increased, highlighting effects on the larval and pupal development, longevity, fecundity, sex-ratio, oviposition behaviour, mobility/orientation, etc. Some of the studies mentioned herein have also analysed the effects of pyrethroids on the emergence rates of parasitoids, but this trait will not be particularly discussed in this chapter since it is an indirect via of quantifying wasp mortality within the host.

\section{Development}

Insecticides may interfere with the development rate of parasitoid preimaginal stages, which can have a large impact on a natural enemy's intrinsic rate of increase $(\mathrm{rm})$ and phenological synchrony with the host or prey (Desneux et al. 2007). Egg-adult development time of Apanteles galleriae (Hymenoptera: Braconidae) reared on Achoria grisella (Lepidoptera: Pyralidae) larvae exposed to different doses of cypermethrin was increased by more than $50 \%$ than those parasitoids that developed on untreated hosts (Ergin et al., 2007). According to these authors, the delay in the parasitoid development may be due to changes in the hormonal milieu of the host (since the larval parasitoid synchronizes the development with the host by making use of host hormones) or to insufficient food supply from the host (due to the cypermethrin-induced decline in diet quality and to the potency of cypermethrin as an antifeedant). Conversely, Symington (2003) observed that the pupation and adult emergence of the larval endoparasitoid, Orgilus lepidus (Hymenoptera: Braconidae), was hastened (approximately $24 \mathrm{~h}$ and $48 \mathrm{~h}$, respectively) when parasitoids were developing in permethrin-treated host larvae. Vieira et al. (2001) did not observe changes in the developmental rate of Trichogramma cordubensis (Hymenoptera: Trichogrammatidae) treated with pyrethroids (deltamethrin and lambda-cyhalothrin) at different preimaginal stages; in this case, the chorion of the host egg most probably provided a protection for the immature stages of the parasitoids, and thus the wasp's preimaginal development was not affected by both pyrethroids.

\section{Longevity}

Reductions in longevity have been generally observed in parasitoids that had been exposed to insecticides when developing inside of hosts (Longley, 1999; Desneux et al., 2006ab; Ergin et al. 2007).

The consequences of reduced longevity on population dynamics were recently emphasized by studies assessing pesticide impacts on arthropods using life table analysis, given that a decrease in survival may result in a strong reduction on the natural enemy's intrinsic rate of increase (Stark et al., 2007b).

Effects on parasitoid longevity may be considered a sublethal effect or latent mortality, depending on the biology of the natural enemy (e.g., proovigenic parasitoids are more likely to reproduce before their premature death than synovigenic wasps, given that proovigenic wasps have a full complement of mature eggs at emergence). According to Bayram et al. (2010), the longevity of Trichogramma busseolae (Hymenoptera: Trichogrammatidae) females was significantly reduced by deltamethrin or cyfluthrin, but the authors refer that such reduction may not affect the reproductive efficacy of the parasitoids under field conditions 


\begin{tabular}{|c|c|c|c|c|}
\hline Parasitoid species & $\begin{array}{c}\text { Pyrethroid } \\
\text { active ingredient }\end{array}$ & Exposure (individuals exposed) & Sublethal effect & Reference \\
\hline Microplitis croceipes (Hym.: Braconidae) & esfenvalerate & Contact with odours (adults) & B (food searching*) & Alyokhin et al. (2010) \\
\hline Telenomus busseolae (Hym.: Scelionidae) & $\begin{array}{c}\text { cyfluthrin } \\
\text { deltamethrin }\end{array}$ & Contact with residues (adults) & $\begin{array}{c}\mathrm{F}^{*}, \mathrm{~L}^{*} \\
\mathrm{~B} \text { (walking and response to host cues*) } \\
\text { OF (emergence rates, sex ratio) }\end{array}$ & Bayram et al. (2010) \\
\hline Cotesia vestalis (Hym.: Braconidae) & permethrin & Spraying host plants (adults) & $\mathrm{B}$ (flight response and foraging behaviour) & Kawazu et al. (2010) \\
\hline Trichogramma cordubensis (Hym.: Trichogrammatidae) & $\begin{array}{c}\text { deltamethrin } \\
\text { lambda-cyhalothrin }\end{array}$ & Spraying (diapausing prepupae) & $\mathrm{L}^{*}, \mathrm{~F}^{*}$ & Garcia et al. (2009) \\
\hline Trichogramma pretiosum (Hym.: Trichogrammatidae) & $\begin{array}{l}\text { betacyflurin } \\
\text { esfenvalerate }\end{array}$ & Spraying host eggs (adults) & $\begin{array}{c}F^{*} \\
\text { OF (fecundity*) }\end{array}$ & Vianna et al. (2009) \\
\hline Apanteles galleriae (Hym.: Braconidae) & cypermethrin & Via the host (host diet) & $\begin{array}{c}\mathrm{L}^{*}, \mathrm{D}^{*} \\
\mathrm{OF} \text { (sex ratio; body size) }\end{array}$ & Ergin et al. (2007) \\
\hline Trichogramma pretiosum (Hym.: Trichogrammatidae) & $\begin{array}{l}\text { alpha-cypermethrin } \\
\text { zeta-cypermethrin } \\
\text { deltamethrin }\end{array}$ & Contact with residues (adults) & $\mathrm{F}^{*}$ & Bastos et al. (2006) \\
\hline Diaeretiella rapae (Hym.: Braconidae) & deltamethrin & $\begin{array}{l}\text { Spraying (aphid mummies) } \\
\text { Contact with residues (adults) }\end{array}$ & $\begin{array}{c}\mathrm{L}^{*} \\
\mathrm{~B} \text { (response to host cues) }\end{array}$ & Desneux et al. (2006a) \\
\hline Aphidius ervi (Hym.: Braconidae) & deltamethrin & $\begin{array}{l}\text { Spraying/topical (aphid mummies) } \\
\text { Contact with residues (adults) }\end{array}$ & $\begin{array}{c}\mathrm{L}^{*} \\
\mathrm{~B} \text { (response to host cues) }\end{array}$ & Desneux et al. (2006b) \\
\hline Trichogramma cordubensis (Hym.: Trichogrammatidae) & deltamethrin & $\begin{array}{c}\text { Spraying } \\
\text { (prepupa within the host) }\end{array}$ & $\begin{array}{c}\text { F, EG } \\
\text { OF (emergence rates*) }\end{array}$ & Garcia et al. (2006) \\
\hline Leptopilina heterotoma (Hym.: Figitidae) & deltamethrin & Contact with residues (adults) & B (walking* and response to host cues*) & Delpuech et al. (2005) \\
\hline Trissolcus grandis (Hym.: Scelionidae) & deltamethrin & $\begin{array}{c}\text { Spraying } \\
\text { (larvae within the host) }\end{array}$ & $\begin{array}{c}\text { L, F } \\
\text { OF (emergence rates, sex ratio) }\end{array}$ & Saber et al. (2005) \\
\hline Aphidius ervi (Hym.: Braconidae) & lambda-cyhalothrin & Contact with residues (adults) & B (response to host cues) & Desneux et al. (2004a) \\
\hline $\begin{array}{l}\text { Diaeretiella rapae (Hym.: Braconidae) } \\
\text { Aphidius matricariae (Hym.: Braconidae) }\end{array}$ & deltamethrin & Contact with residues (adults) & B (oviposition behaviour) & Desneux et al. (2004b) \\
\hline Aphidius ervi (Hym.: Braconidae) & lambda-cyhalothrin & Contact with residues (adults) & $\begin{array}{c}\text { B (response to host } \text { cues }^{*} \text { ) } \\
\text { B (oviposition experience and behaviour*) }\end{array}$ & Desneux et al. (2003) \\
\hline Trissolcus basalis (Hym.: Scelionidae) & deltamethrin & Contact with residues (adults) & B (walking* and response to host cues*) & Salerno et al. (2002) \\
\hline Trichogramma cacoeciae (Hym.: Trichogrammatidae) & deltamethrin & Contact with residues (adults) & $\mathrm{F}^{*}$ & Youssef et al. (2004) \\
\hline Orgilus lepidus (Hym.: Braconidae) & permethrin & $\begin{array}{c}\text { Spraying } \\
\text { (immature stages within the host) }\end{array}$ & $D^{*}$ & Symington (2003) \\
\hline Trichogramma brassicae (Hym.: Trichogrammatidae) & deltamethrin & Contact with residues (adults) & B (sex pheromonal communication*) & Delpuech et al. (2001) \\
\hline Trichogramma cordubensis (Hym.: Trichogrammatidae) & $\begin{array}{l}\text { deltamethrin } \\
\text { lambda-cyhalothrin }\end{array}$ & $\begin{array}{c}\text { Spraying } \\
\text { (immature stages within the host) }\end{array}$ & $\mathrm{L}, \mathrm{D}$ & Vieira at al. (2001) \\
\hline
\end{tabular}

Table 1. Summary of literature published from 2000-2010 (data from ISI Web of Knowledge database) regarding the sublethal effects of pyrethroids on parasitoids; $\mathrm{L}=$ Longevity, $\mathrm{F}=$ Fecundity, EG= egg maturation, $\mathrm{D}=$ Development, $\mathrm{B}=$ Behaviour (specified), $\mathrm{OF}=$ offspring traits (specified); *Significant effects.

because the parasitoid lays most of its eggs within $72 \mathrm{~h}$ of emergence (longevity of pyrethroid-treated wasps averaged 11 days). On the other hand, Desneux et al. (2006ab) confirmed a high risk of deltamethrin treatments for aphid parasitoids [Diaeretiella rapae and Aphidius ervi (Hymenoptera: Braconidae)] that may recolonize the treated crop when emerging from the mummies, since deltamethrin induced a decrease in the longevity of emerged individuals and of the adults that walked on treated leaves, and thus, potential fecundity will also be limited. In the case of $A$. ervi, the authors have calculated a Population Survival Index (that takes into account the percentage of aphid of mummified parasitoids, the percentage of parasitoid emergence from the mummies, the percentage of emerged 
adults that survived more than $48 \mathrm{~h}$ and the percentage of adults that survived to residual exposure) which foresee that only $5 \%$ of the parasitoid population would be able to recolonize a deltamethrin-treated field (at the recommended rate) by the "vertical recruitment" process (Desneux et al., 2006b); for D. rapae this index dropped the prediction to $3 \%$ (Desneux et al., 2006a).

\section{Fecundity, Egg maturation and Sex-ratio}

Reductions in fecundity due to pyrethroids may be due to both physiological (e.g., by interfering with oogenesis) and behavioural (e.g., by interfering with host acceptance) factors. Although several authors have shown that pyrethroids reduce the fecundity of parasitoids (Youssef et al., 2004; Bastos et al., 2006; Vianna et al., 2009; Bayram et al., 2010), the physiological and behavioural causes of such reduction are not usually discussed. Bastos et al. (2006) showed that although the pupal stage of Trichogramma pretiosum (Hymenoptera: Trichogrammatidae) developing in Sitotroga cerealella (Lepidoptera: Gelechiidae) eggs was less susceptible to alpha-cypermethrin and deltamethrin than parasitoids developing in Ephestia kuehniella (Lepidoptera: Pyralidae), the fecundity is highly reduced by these pyrethroids regardless of the host species. These authors hypothesized that the differences in the structure and composition of host egg chorions may have provided a higher protection for the parasitoids developing inside S. cerealella eggs, but variations in egg structure, however, would not account for the difference in the ability of the adults to parasitize eggs. Bayram and co-authors (2010) showed that T. busseolae females exposed to cyfluthrin parasitized significantly fewer eggs than untreated females, whereas deltamethrin did not significantly affect the wasp's fecundity; nevertheless, neither the emergence rates nor the sex ratio of the offspring was affected by both insecticides. These authors hypothesized that the reduction in fecundity was probably due to perturbations in behaviour (cyfluthrin also negatively affected the parasitoid behavioural responses to host cues) rather than the reduction of egg load. The influence of deltamethrin on the reproduction of T. cordubensis was investigated by Garcia et al. (2006) when studying egg maturation and daily fecundity of deltamethrin-treated wasps (prepupal stage) and emergence rates of their offspring. In this study, the authors demonstrated that although daily fecundity and egg maturation patterns were not modified by the pyrethroid, the offspring emergence rates of wasps that started the vitllelogenesis upon emergence from the host were most probably reduced by deltamethrin residues resting on the chorion of the host egg. Vianna et al. (2009) observed that the fecundity of T. pretiosum was significantly reduced by pyrethroids (betacyflurin and esfenvalerate) in two consecutive generations, despite the fact that only the first one contacted with pyrethroid-treated host eggs. Even though Saber et al. (2005) had observed a significant reduction in the adult emergence of Trissolcus grandis (Hymenoptera: Scelionidae) from host eggs treated with deltamethrin, the pyrethroid did not negatively affect the longevity or fecundity of emerged females.

Changes in the sex-ratio of parasitoids exposed to pyrethroids are mainly related to differential survival as a function of sex, either during development or as adults (Saber et al., 2005), or an effect during sex determination in haplodiploid species, in which the parasitoid defines the sex of the progeny when laying the eggs, a behaviour that can be disrupted by the pyrethroid. Nevertheless, when endoparasitoids are exposed to pyrethroids during the preimaginal stages it seems that the sex-ratio is not usually disrupted, as the results by Saber et al. (2005), Ergin et al. (2007) and Bayram et al. (2010) underline. 


\subsection{Behavioural traits}

The effectiveness of a parasitoid in biological control is, to great extent, dependent on the ability of the parasitoid ability to locate, recognize and parasitize the host. Successful parasitisation has been divided into several phases, mediated by a variety of chemical and physical stimuli: host-habitat location, host location, host acceptance and host regulation (Nordlund, 1994). The recognition of chemical stimuli (e.g., host-produced cues) by foraging parasitoids plays an important role to their success on finding and parasitizing hosts. The process of odour detection of these chemical stimuli, and consequent parasitoid responses, is dependent on neural transmissions, which are expected to be affected by neurotoxic insecticides, such as pyrethroids. The recognition that the evaluation of the impacts of pyrethroids on the behavioural traits of parasitoids is also of high relevance in IPM, has conducted to an increase in the number of published studies in the past decade.

\section{Mobility and Orientation}

Pyrethroids may interfere by direct intoxication with the mobility of parasitoids, producing uncoordinated movements, trembling and even a knockdown effect; these neurotoxic insecticides may also change their mobility patterns such as, angular speed and linear speed. Disruption in the detection of habitat and host chemical cues by pyrethroids also interferes with the orientation of the parasitoids, resulting in behaviours like parasitoid arrestment or repellence (Desneux et al., 2007). Salerno et al. (2002) found significant sublethal effects of deltamethrin on the arrestment response and walking behaviour of Trissolcus basalis (Hymenoptera: Scelionidae) to a contact kairomone (chemical traces) from its host, Nezara viridula L. (Heteroptera: Pentatomidae). These authors have shown that T. basalis females that had been exposed to a low concentration of deltamethrin reduced their linear speed and, in the presence of host cues, females spent less time on host patches but their walking speed was not altered. In face of these results, the authors hypothesize that the sublethal effect of deltamethrin on host foraging may decrease T. basalis efficacy in controlling $N$. viridula. Delpuech et al. (2005) also found that deltamethrin increased the arrestment response of Leptoplilina heterotoma (Hymenoptera: Figitidae) to host cues and reduced their linear speed. The authors explained that the observed increase in the arrestment response is coherent with pyrethroid intoxication, given that deltamethrin induces a prolongation of nervous stimulations each time neurons are stimulated by the perception of host cues. Bayram et al. (2010) observed that cyfluthrin-treated T. busseolae females failed to respond to the host sex pheromone, although deltamethrin-treated females responded similarly to untreated females. These authors have also evaluated the sublethal effects of both pyrethroids on the parasitoid arrestment behaviours (residence time, linear speed) in an open arena containing abdominal scales from virgin female moths (which are a source of host-contact kairomonal cues), but no significant differences were found. According to Bayram et al. (2010), the fact deltamethrin had no effect on sex-pheromone detection by the parasitoid is probably related to the experimental procedure: all behavioural observations undertaken on T. busseolae were performed $12 \mathrm{~h}$ after the exposure, a period that may have enabled parasitoids to compensate for sublethal effects of deltamethrin. Desneux et al. (2006ab) also confirmed that the orientation behaviour A. ervi and D. rapae toward aphidinfested plants is not altered after parasitoid exposure to deltamethrin, suggesting that the greater vigour in the surviving insects may explain this lack of effect; similar results were observed by Desneux et al. (2004a) when analysing A. ervi responses to the odour from aphid-infested plants after parasitoid exposure to increasing doses of lambda-cyhalothrin 
residues. In very recent study, Kawazu et al. (2010) demonstrated that permethrin had an inhibitory effect on Cotesia vestalis (Hymenoptera: Braconidae) flight response, given that wasps showed significant preference for host-infested plants over insecticide-treated plants. Moreover, searching time was significantly shorter and the mortality of $C$. vestalis adults on the insecticide-treated plants significantly higher than in the control plants (treated with distilled water).

\section{Oviposition behaviour}

Once a host is detected, the female parasitoid evaluates its suitability, by checking the presence of the physiological conditions necessary for the development and growth of her progeny. Host acceptance or rejection depends on a variety of cues perceived by the female parasitoid during antennal contact with the host and/or ovipositor insertion (Godfray, 1994). All the behaviours involved in this process, from the detection of host chemical cues to oviposition, involve neural transmissions, which are targeted by neurotoxic insecticides, and thus pyrethroids have been reported to disrupt both sensory perception and motor functions of parasitoids. Such disruptions were demonstrated by Desneux et al. (2003) when studying the sublethal effects of lambda-cyhalothrin on host searching (at a low sublethal dose of exposure) of $A$. ervi females without oviposition experience and oviposition behaviours (at a lethal dose of exposure) of oviposition experienced females; however, no effect was observed on the orientation behaviour toward aphid-infested plants when females had an oviposition experience prior to the olfactometer test. Furthermore, all the behavioural effects disappeared $24 \mathrm{~h}$ after the end of insecticide exposure. The results obtained by these authors draw attention to the fact that orientation and oviposition behaviours of parasitoids may be disturbed by pyrethroids, depending on the dose, the parasitoid experience and the type of behaviour. Conversely, the oviposition behaviour (both frequencies and behavioural sequences) of D. rapae and A. matricariae (Hymenoptera: Braconidae) on aphid-infested plants and patch-time allocation were not disturbed following exposure to deltamethrin residues (Desneux et al., 2004b), regardless of the dose. According to these authors the unexpected lack of effects after deltamethrin exposure can have two explanations: either the deltamethrin molecules did not alter the functions necessary for host-handling behaviour, or the surviving insects were less susceptible (reflecting differences in parasitoid vigour or in genetically determined susceptibility to pesticides).

\section{Communication}

Disruption by pyrethroids of sexual communication and mate-finding in insect parasitoids may be due to changes in the capacity to create and/or perceive chemical stimulus involved in the communication process (Desneux et al. 2007)). According to Delpuech et al. (1999) deltamethrin induced an increase of the arrestment of Trichogramma brassicae (Hymenoptera: Trichogrammatidae) males by the sex pheromone when only males but not females were exposed a sublethal dose of the insecticide; when the pheromone was emitted by treated females, deltamethrin induced a decrease of the response of non insecticide-treated males (Delpuech et al., 1999). Afterwards, Delpuech and co-authors (2001) demonstrated that these effects are counterbalanced when both sexes are exposed to an equal sublethal dose of deltamethrin (that causes theoretically $0.1 \%$ of mortality), being the mean response to pheromone extract not significantly different from that of controls. However, the kinetics of their response was modified by the pyrethroid: for controls, the mean response to the 
pheromone regularly decreased during time (probably due to an increasing saturation of pheromone receptors), while the mean response of deltamethrin-treated males stabilized throughout time. As a result, the decrease of the emission of sex pheromone by treated females would be compensated by the increased receptivity of treated males.

\section{Food searching}

Volatiles present in the environment, such as insecticide odours, may interfere with the specific olfactory cues (such as odours from food sources) through repellent and/or masking action, or may enhance them by providing a contrasting background against which the informative odours become easier to distinguish. This issue was very recently investigated by Aleyokin et al. (2010) using the food-searching behaviour of Microplitis croceipes (Hymenoptera: Braconidae) in laboratory arenas in the presence of odours from distinct pesticides as a model system. Their results showed that the odour of esfenvalerate decreased $M$. croceipes response to food odours, being this effect less pronounced for the unfed parasitoids. In face of such behaviour, the authors suggest that provision of food may potentially be used to keep beneficial natural enemies away from insecticide-treated areas.

\subsection{Other effects}

Controlling diapause in egg parasitoids increases the efficiency of their long-term storage with important implications for their use in pest control programs, by allowing producers to stockpile the parasitoids for release in the growing season (Rundle et al. 2004), and therefore reduce the costs of mass rearing. However, when storing diapausing wasps one must not disregard the biological traits of post-diapausing insects, such as their susceptibility to pesticides, because poor-quality parasitoids could yield low efficiency in pest management programs. A recent study by Garcia et al. (2009) demonstrated that emergence rate, longevity and fecundity of pyrethroid (deltamethrin and lambda-cyhalothrin) treated diapausing prepupae of $T$. cordubensis generally decreased with increasing duration in cold storage. Emergence rates were particularly affected regardless of the period of cold storage, given that both pyrethroids significantly reduced the emergence rates $(<25 \%)$ compared to the control (emergence varied from $83 \%$ to $89 \%$ ). These results highlight the fact that the sublethal effects of pyrethroids on long-term cold stored diapausing wasps are more noteworthy that on non cold stored parasitoids and thus such effects must not be disregarded when considering the use of cold-stored wasps in IPM programs. Another important issue when analysing sublethal effects of insecticides is the variation in susceptibility that occurs between distinct populations of parasitoids. The results by Vianna et al. (2009) showed that the impact of pyrethroids on distinct populations of T. pretiosum can vary significantly, which indicates that the tolerance or resistance to insecticides may be related to biotic (adaptability and intrinsic capacity of the population in a specific environment) and abiotic (environmental conditions) factors of their origin place. Therefore, and as suggested by the authors, different populations of parasitoids should be used when evaluating insecticide toxicity.

\section{Future prospects and needs}

Although insecticides still dominate commercial agriculture, increased public awareness of their deleterious non-target effects, including those on human health, provides a strong 
incentive for the use of alternatives. Still, complete pesticide replacement by non-chemical methods is unlikely to happen in the near future. Therefore, compatibility with chemical control is essential for the increased adoption of alternative methods, such as the integration of biological and chemical controls. In general, field studies have shown that natural enemies, particularly adult parasitoids, are highly affected by pyrethroids, even when these insecticides are applied at a low dosage (e.g., Ruano et al., 2010). However, in the case of endoparasitoids, laboratory trials generally have shown that when pyrethroids are applied on parasitized hosts, their impact on the parasitoids is lowered (e.g., Longley, 1999; Sterk et al., 1999). Even so, their impact on sublethal effects on natural enemies, and consequently the success of biological control programs, can be as deleterious as mortality. Most of the studies for pyrethroid sublethal effects report effects in behavioural and physiological traits of parasitoids in laboratory trials, which can severely disrupt intraspecific or interspecific interactions. Such disruptions generally decrease the success of biological control or IPM programs since they usually interfere with the natural enemies' long-term survival and reproduction and, consequently, reduce their effectiveness in controlling the targeted pest. However, in some field and semi-field studies pyrethroid residues where shown to have no effect on the limitation of parasitoids when recolonizing treated fields (e.g., Desneux et al., 2005) and so, in a perspective of integrated pest management, pyrethroids and parasitoids can have additive effects in controlling the targeted pest. Increasing temporal and spatial separation between insecticide treatments and parasitoids is instrumental for their integration in pest management programs, and certainly behavioural manipulation may provide an additional tool for achieving this goal. The combination of knowledge on physiological and behavioural sublethal effects of pyrethroids, and as well of pesticides in general, provides valuable information for IPM decision-making, as highlighted by most of the studies discussed in this chapter. The integration of these effects in an analysis of population fitness, specifically focused on the population growth rate of the natural enemies, would also provide a more holistic picture of the ability of biocontrol agents to manage insect

pest populations. Therefore, predicting the overall effects of pyrethroids on natural enemies, including mortality and sublethal effects, confirmed by field data, followed with demographic and modelling analysis, is the safest via, although complex, to develop and use truly selective insecticides that cause minimal disruption to naturally occurring biological control agents.

\section{References}

Alyokhin, A.; Makatiani, J. \& Takasu, K. (2010). Insecticide odour interference with foodsearching behaviour of Microplitis croceipes (Hymenoptera: Braconidae) in a laboratory arena. Biocontrol Science and Technology, 20(3): 317-329.

Bayram, A.; Salerno, G.; Onofri, A. \& Conti, E. (2010). Sub-lethal effects of two pyrethroids on biological parameters and behavioural responses to host cues in the egg parasitoid Telenomus busseolae. Biological Control, 53:153-160.

Bastos, C.S.; Almeida, R.P. \& Suinaga, F.A. (2006) Selectivity of pesticides used on cotton (Gossypium hirsutum) to Trichogramma pretiosum reared on two laboratory-reared hosts. Pest Management Science, 62: 91-98.

Brunner, J.F.; Dunley, J.E.; Doerr, M.D. \& Beers, E.H. (2001). Effect of pesticides on Colpoclypeus florus (Hymenoptera: Eulophidae) and Trichogramma platneri 
(Hymenoptera: Trichogrammatidae), parasitoids of leafrollers in Washington. Journal of Economic Entomology, 94(5): 1073-1083.

Collier, T. \& Steenwyk R.V. (2004). A critical evaluation of augmentative biological control. Biological Control, 31: 245-256.

Cross, J.V.; Solomon, M.G.; Babandreier, D.; Blommers, L.; Easterbrook, M.A.; Jay, C.N.; Jenser, G.; Jolly, R. L.; Kuhlmann, U.; Lilley, R.; Olivella, E.; Toepfer, S. \& Vidal, S. (1999). Biocontrol of Pests of Apples and Pears in Northern and Central Europe: 2. Parasitoids. Biocontrol Science and Technology, 9: 277-314.

Davies, T. G. E.; Field, L. M., Usherwood, P. N. R. \& Williamson, M. S. (2007). DDT, Pyrethrins, Pyrethroids and Insect Sodium Channels. IUBMB Life, 59(3): 151 - 162.

Delpuech, J.M.; Legallet, B.; Terrier, O. \& Fouillet, P. (1999). Modifications of the sex pheromonal communication of Trichogramma brassicae by a sublethal dose of deltamethrin. Chemosphere, 38(4): 729-739.

Delpuech, J.M.; Legallet, B. \& Fouillet, P. (2001). Partial compensation of the sublethal effect of deltamethrin on the sex pheromonal communication of Trichogramma brassicae. Chemosphere, 42: 985-991.

Delpuech, J.M.; Bardon, C. \& Boulétreau, M. (2005). Increase of the Behavioral Response to Kairomones by the Parasitoid Wasp Leptopilina heterotoma Surviving Insecticides. Archives of Environmental Contamination and Toxicology, 49:186-191.

Denholm, I.; Pickett, J.A. \& Devonshire, A.L. (2001). Insecticide Resistance: From Mechanisms to Management, CABI and The Royal Society publishing, ISBN 0-85199-367-2, UK.

Desneux, N.; Decourtye, A. \& Delpuech, J.M. (2007). The Sublethal Effects of Pesticides on Beneficial Arthropods. Annual Review of Entomology, 52: 81-106.

Desneux, N.; Ramirez-Romero, R. \& Kaiser, L. (2006a). Multistep Bioassay to Predict Recolonization Potential of Emerging Parasitoids after a Pesticide Treatment. Environmental Toxicology and Chemistry, Vol. 25 (10): 2675-2682.

Desneux, N.; Denoyelle, R. \& Kaiser, L. (2006b). A multi-step bioassay to assess the effect of the deltamethrin on the parasitic wasp Aphidius ervi. Chemosphere, 65: 1697-1706.

Desneux, N.; Fauvergue, X.; Dechaume-Moncahrmont, X.; Kerhoas, L.; Ballanger, Y. \& Kaiser, L. (2005). Diaeretiella rapae Limits Myzus persicae Populations After Applications of Deltamethrin in Oilseed Rape. Journal of Economic Entomology, 98(1): 9-17.

Desneux, N.; Rafalimanana, H. \& Kaiser, L. (2004a). Dose-response relationship in lethal and behavioural effects of different insecticides on the parasitic wasp Aphidius ervi. Chemosphere, 54: 619-627.

Desneux, N. ; Wajnberg, E. ; Fauvergue, X. ; Privet, S. \& Kaiser, L. (2004b). Oviposition behaviour and patch-time allocation in two aphid parasitoids exposed to deltamethrin residues. Entomologia Experimentalis et Applicata, 112: 227-235.

Desneux, N.; Pham-Delègue, M. \& Kaiser, L. (2003). Effects of sub-lethal and lethal doses of lambda-cyhalothrin on oviposition experience and host-searching behaviour of a parasitic wasp, Aphidius ervi. Pest Management Science, 60:381-389.

Ergin, E.; Er, A.; Uçkan, F. \& Rivers, D.B. (2007). Effect of Cypermethrin Exposed Hosts on Egg-Adult Development Time, Number of Offspring, Sex Ratio, Longevity, and Size of Apanteles galleriae Wilkinson (Hymenoptera : Braconidae). Belgian Journal of Zoology, 137 (1): 27-31. 
Essig, K. \& Zhao, Z.J. (2001). Preparation and Characterization of a Pyrethrum Extract Standard. LCGC, 19(7): 722-730.

Garcia, P.; Pereira, N. \& Oliveira, L. (2009). Side-effects of organic and synthetic pesticides on cold-stored diapausing prepupae of Trichogramma cordubensis. BioControl, 54: 451-458.

Garcia, P.; Cabral, S.; Oliveira, L. \& Rodrigues, A. (2006). Effects of deltamethrin on the reproduction of Trichogramma cordubensis (Hymenoptera: Trichogrammatidae). Biocontrol Science and Technology, 16(7): 699-708.

Gauld, I. \& Bolton, B. (1988). The Hymenoptera, Oxford University Press, ISBN 0-19-858521, USA.

Gentz, M.C; Murdoch, G. \& King, G.F. (2010). Tandem use of selective insecticides and natural enemies for effective, reduced-risk pest management. Biological Control, 52: 208-215.

Godfray, H.C.J. (1994). Parasitoids: Behavioural and evolutionary ecology, Princeton University Press, ISBN 0-691-00047-6, UK.

Greathead, D.J. (1986). Parasitoids in classical biological control, In: Insect parasitoids, Waage J. \& Greathead D. (Ed.), 289-318, Academic Press, ISBN 0-12-728900-3, UK.

Gunasekara, A.S. (2004). Environmental Fate of Pyrethrins, California Environmental Protection Agency (Cal/EPA), Department of Pesticide Regulation. Sacramento, CA, U.S.

Hassan, S.A. (1993). The mass rearing and utilization of Trichogramma to control lepidopterous pests: achievements and outlook. Pesticide Science, 37: 387-391.

Hewa-Kapuge, S.; McDougall, S. \& Hoffmann, A. (2003). Effects of methoxyfenozide, indoxacarb, and other insecticides on the beneficial egg parasitoid Trichogramma nr. brassicae (Hymenoptera: Trichogrammatidae) under laboratory and field conditions. Journal of Economic Entomology, 96(4): 1083-1090.

Housset, P. \& Dickmann, R. (2009). A promise fulfilled - pyrethroid development and the benefits for agriculture and human health. Bayer CropScience Journal, 62/2009, 2: 135-144.

Kok, L.T. \& Acosta-Martinez, J.A. (2001). Differential susceptibility of Cotesia orobenae, a parasitoid of the cross-striped cabbageworm,to commonly used insecticides in Cruciferae. BioControl, 46: 419-426.

Kawazu, K.; Shimoda, T.; Kobori1, Y.; Kugimiya, S.; Mukawa, S. \& Suzuki, Y. (2010). Inhibitory effects of permethrin on flight responses, host-searching, and foraging behaviour of Cotesia vestalis (Hymenoptera: Braconidae), a larval parasitoid of Plutella xylostella (Lepidoptera: Plutellidae). Journal of Applied Entomology, 134: 313322.

Langley, M. \& Stark, J.D. (1996). Analytical techniques for quantifying direct, residual, and oral exposure of an Insect parasitoid to an organophosphate insecticide. Bulletin of Environmental Contamination and Toxicology, 57:683-690.

Li-Ying, L. (1994). Worldwide use of Trichogramma for biological control on different crops: A survey, In: Biological Control with egg parasitoids, Wajnberg E. \& Hassan S. (Ed.), 37-53, CAB International, ISBN 0-851-98896-2, UK.

Longley, M. (1999). A review of pesticide effects upon immature aphid parasitoids within mummified hosts. International Journal of Pest Management, 45(2): 139-145. 
Nordlund, D.A. (1994). Habitat location by Trichogramma, In: Biological Control with egg parasitoids, Wajnberg E. \& Hassan S. (Ed.), 155-163, CAB International, ISBN 0-85198896-2, UK.

Pinto, J.D. \& Stouthamer, R. (1994). Systematics of the Trichogrammatidae, In: Biological Control with egg parasitoids, Wajnberg E. \& Hassan S. (Ed.), 5-28, CAB International, ISBN 0851988962, UK.

Pintureau, B.; Louis, C. \& Chapelle, L. (1993). Symbiose entre microorganismes et Trichogrammes (Hym. Trichogrammatidae): Intérêt pour a lutte biologique. Bulletin de la Société Zoologique de France, 118(2): 159-167.

Prabhaker, N.; Morse, J.G.; Castle, S.J.; Naranjo, S.E.; Henneberry, T.J. \& Toscano, N.C. (2007). Toxicity of Seven Foliar Insecticides to Four Insect ParasitoidsAttacking Citrus and Cotton Pests. Journal of Economic Entomology, 100(4): 1053-1061.

Quicke, D.L.J. (1997). Parasitic wasps, Chapman \& Hall, ISBN 0-412-58350-X, UK.

Raposo, F.; Oliveira, L. \& Garcia, P. (2003). Susceptibility to Insecticides of Glyptapanteles militaris (Hymenoptera: Braconidae), a Parasitoid of Pseudaletia unipuncta (Lepidoptera: Noctuidae). Biocontrol Science and Technology, 13: 261-267-

Reigart, J.R. \& Roberts, J.R. (1999). Recognition and management of pesticide poisonings. $5^{\text {th }}$ edition. U.S. Environmental Protection Agency Publication EPA-735-R-98-003. Washington, DC, U.S.

Ruano; F.; Campos, M.; Sánchez-Raya, A.J. \& Aránzazu Peña, A. (2010). Olive trees protected from the olive bark beetle, Phloeotribus scarabaeoides (Bernard 1788) (Coleoptera, Curculionidae, Scolytinae) with a pyrethroid insecticide: Effect on the insect community of the olive grove. Chemosphere 80: 35-40.

Rundle, B.J.; Thomson, L.J. \& Hoffmann, A.A. (2004). Effects of cold storage on field and laboratory performance of Trichogramma carverae (Hymenoptera: Trichogrammatidae) and the response of three Trichogramma spp. (T. carverae, T. nr. brassicae, and T. funiculatum) to cold. Journal of Economic Entomology, 97: 213-221.

Saber, M.; Jalil Hejazi, M.; Kamali, K. \& Moharramipour, S. (2005). Lethal and Sublethal Effects of Fenitrothion and Deltamethrin Residues on the Egg Parasitoid Trissolcus grandis (Hymenoptera: Scelionidae). Journal of Economic Entomology, 98(1): 35-40.

Salerno, G.; Colazza, S. \& Conti, E. (2002). Sub-lethal effects of deltamethrin on walking behaviour and response to host kairomone of the egg parasitoid Trissolcus basalis. Pest Management Science, 58: 663-668.

Smith, S. (1996). Biological control with Trichogramma: Advances, Successes, and potential of their use. Annual Review of Entomology, 41: 375-406.

Smith, K.; Evans D.A. \& El-Hiti, G.A. (2008). Role of modern chemistry in sustainable arable crop protection. Philosophical Transactions of the Royal Society, B, 363: 623-637.

Stark, J.D.; Vargas, R.I. \& Banks, J.E. (2007a). Incorporating ecologically relevant measures of pesticide effect for estimating the compatibility of pesticides and biocontrol agents. Journal of Economic Entomology, 100: 1027-1032.

Stark, J.D.; Sugayama, R.L. \& Kovaleski, A. (2007b). Why demographic and modeling approaches should be adopted for estimating the effects of pesticides on biocontrol agents. BioControl, 52: 365-374.

Sterk, G.; Hassan, S.A.; Baillod, M.; Bakker, F.; Bigler, F.; Blümel, S.; Bogenschütz, H.; Boller, E.; Bromand, B.; Brun, J.; Calis, J.N.M.; Coremans-Pelseneer, J.; Duso, C.; Garrido, A.; Grove, A.; Heimbach, U.; Hokkanen, H.; Jacas, J.; Lewis, G.; Moreth, L.; Polgar, 
L.; Roversti, L.; Samsoe-Pettersen, L.; Sauphanor, B.; Schaub, L.; Stäubli, A.; Tust, J.J.; Vainio, A.; Van De Veire, M.; Viggiani, G.; Viñuela, E. \& Vogt, H. (1999). Results of the seventh joint pesticide testing programme carried out by the IOBC/WPRSWorking Group "Pesticides and beneficial organisms". BioControl, 44: 99-117.

Stinner, R.E. (1977). Efficacy of inundative releases. Annual Review of Entomology, 22: 515-531.

Stouthamer, R. (1993). The use of sexual versus asexual wasps in biological control. Entomophaga, 38(1): 3-6.

Stouthamer, R. \& Werren J.H. (1993). Microbes associated with parthenogenesis in wasps of the genus Trichogramma. Journal of Invertebrate Pathology, 61: 6-9.

Stouthamer, R.; Breeuwer, J.; Luck, R.F. \& Werren, J. (1993). Molecular identification of microorganisms associated with parthenogenesis. Nature, 361: 66-68.

Symington, C.A. (2003). Lethal and sublethal effects of pesticides on the potato tuber moth, Phthorimaea operculella (Zeller) (Lepidoptera: Gelechiidae) and its parasitoid Orgilus lepidus Muesebeck (Hymenoptera: Braconidae). Crop Protection, 22: 513-519.

Tillman, P.G. \& Mulrooney, J.E. (2000). Effect of Selected Insecticides on the Natural Enemies Coleomegilla maculata and Hippodamia convergens (Coleoptera: Coccinellidae), Geocoris punctipes (Hemiptera: Lygaeidae), and Bracon mellitor, Cardiochiles nigriceps, and Cotesia marginiventris (Hymenoptera: Braconidae) in Cotton. Journal of Economic Entomology, 93(6): 1638-1643.

Todd, G.D.; Wohlers, D. \& Citra, M. (2003). Toxicology Profile for Pyrethrins and pyrethroids, Agency for Toxic Substances and Disease Registry (ATSDR), Department of Health and Human Services. Atlanta, GA, U.S.

Van Lenteren, J.C. (1986). Parasitoids in the greenhouse: Successes with seasonal inoculative release systems, In: Insect parasitoids, Waage J. \& Greathead D. (Ed.), 341-374, Academic Press, ISBN 0-12-728900-3, UK.

Vianna, U.R.; Pratissoli, D.; Zanuncio, J.C.; Lima, E.R.; Brunner, J.; Pereira, F.F. \& Serra, J.E. (2009). Insecticide toxicity to Trichogramma pretiosum (Hymenoptera: Trichogrammatidae) females and effect on descendant generation. Ecotoxicology, 18:180-186.

Vieira, A., Oliveira, L. \& Garcia, P. (2001). Effects of Conventional Pesticides on the Preimaginal Developmental Stages and on Adults of Trichogramma cordubensis (Hymenoptera: Trichogrammatidae). Biocontrol Science and Technology, 11: 527- 534.

Wang, H.Y.; Yanga, Y.; Sua, J.Y.; Shena, J.L.; Gaoa, C.F. \& Zhub, Y.C. (2008). Assessment of the impact of insecticides on Anagrus nilaparvatae (Pang et Wang) (Hymenoptera: Mymaridae), an egg parasitoid of the rice planthopper, Nilaparvata lugens (Hemiptera: Delphacidae). Crop Protection, 27: 514-522.

Wirtz, K.; Bala, S.; Amann, A. \& Elbert, A. (2009). A promise extended - future role of pyrethroids in agriculture. Bayer CropScience Journal, 62/2009, 2: 145-158.

Youssef, A.I.; Nasr, F.N.; Stefanos, S.S.; Elkhair, S.S.A.; Shehata, W.A.; Agamy, E.; Herz, A. \& Hassan, S.A. (2004). The side-effects of plant protection products used in olive cultivation on the hymenopterous egg parasitoid Trichogramma cacoeciae Marchal. Journal of Applied Entomology, 128(9-10): 593-599. 


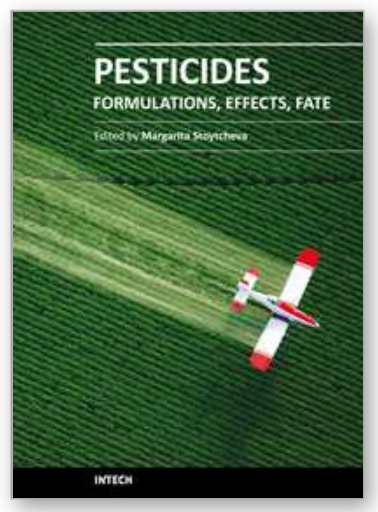

\author{
Pesticides - Formulations, Effects, Fate \\ Edited by Prof. Margarita Stoytcheva
}

ISBN 978-953-307-532-7

Hard cover, 808 pages

Publisher InTech

Published online 21, January, 2011

Published in print edition January, 2011

This book provides an overview on a large variety of pesticide-related topics, organized in three sections. The first part is dedicated to the "safer" pesticides derived from natural materials, the design and the optimization of pesticides formulations, and the techniques for pesticides application. The second part is intended to demonstrate the agricultural products, environmental and biota pesticides contamination and the impacts of the pesticides presence on the ecosystems. The third part presents current investigations of the naturally occurring pesticides degradation phenomena, the environmental effects of the break down products, and different approaches to pesticides residues treatment. Written by leading experts in their respective areas, the book is highly recommended to the professionals, interested in pesticides issues.

\title{
How to reference
}

In order to correctly reference this scholarly work, feel free to copy and paste the following:

Patrícia Garcia (2011). Sublethal Effects of Pyrethroids on Insect Parasitoids: What We Need to Further Know, Pesticides - Formulations, Effects, Fate, Prof. Margarita Stoytcheva (Ed.), ISBN: 978-953-307-532-7, InTech, Available from: http://www.intechopen.com/books/pesticides-formulations-effects-fate/sublethal-effects-ofpyrethroids-on-insect-parasitoids-what-we-need-to-further-know

\section{INTECH}

open science | open minds

\section{InTech Europe}

University Campus STeP Ri

Slavka Krautzeka 83/A

51000 Rijeka, Croatia

Phone: +385 (51) 770447

Fax: +385 (51) 686166

www.intechopen.com

\section{InTech China}

Unit 405, Office Block, Hotel Equatorial Shanghai

No.65, Yan An Road (West), Shanghai, 200040, China

中国上海市延安西路65号上海国际贵都大饭店办公楼 405 单元

Phone: +86-21-62489820

Fax: $+86-21-62489821$ 
(C) 2011 The Author(s). Licensee IntechOpen. This chapter is distributed under the terms of the Creative Commons Attribution-NonCommercialShareAlike-3.0 License, which permits use, distribution and reproduction for non-commercial purposes, provided the original is properly cited and derivative works building on this content are distributed under the same license. 